\title{
Antepfıstığında Toprak İşleme Yöntemlerinin Yabancı Ot Yoğunluğu ve Ürün Verimine Etkisi
}

\author{
Hasan Cem BÍLìM ${ }^{1}$, Tayfun KORUCU ${ }^{2}$ \\ ${ }^{1}$ Antepfistığı Araştırma İstasyonu Müdürlüğü, Gaziantep \\ ${ }^{2} \mathrm{KSÜ}$, Ziraat Fakültesi, Biyosistem Mühendisliği Bölümü, Kahramanmaraş
}

Geliș (Received): 21.04.2015

Kabul (Accepted): 19.02.2016

\begin{abstract}
ÖZET: $\mathrm{Bu}$ çalışmada antepfıstığı bahçelerinde toprak işleme uygulamasının verim ve yabancı otlanma üzerindeki etkileri ve ekonomik analiz değerlendirilmesi amaçlanmıştır. Araştırma 2006-2008 yıllarında Antepfıstığı Araştırma Enstitüsü Müdürlüğü’ne bağlı Fıstıklık işletmesinde yürütülmüştür. Toprak işleme uygulamalarının verim ve yabancı ot yoğunluğu üzerindeki etkisinin istatistiksel olarak önemli olmadığı görülmüştür. Bununla birlikte yabanc1 ot kaplama alanlarının uygulamalar arasında \%5 önem seviyesinde istatistiksel olarak farklı olduğu, buna göre T1 ve T2 uygulamalarında yabancı otların daha az gelişme olanağı bulduğu görülmüştür. Ekonomik analiz her uygulamaya ait gelir/gider oranı dikkate alınarak yapılmıştır. Bunun sonucunda en düşük ve en yüksek gelir/gider oranı sırası ile 1.89 ve 2.70 ile T3 ve T1 uygulamalarında elde edilmiştir.
\end{abstract}

Anahtar Kelimeler: Antepfistı̆̆ı, yabancı ot yoğunluğu, toprak işleme, verim

\section{The Effects of the Tillage Methods on the Weed Density and Yield in the Pistachio Orchards}

ABSTRACT: The purposes of this study were to evaluate the effect of the tillage on the yield, weed density and economical analyzes of methods in the Pistachio Orchards. The field experiments were conducted between 20062008 years on an orchard at Pistachio Research Institute. The yield and weed density were not significantly impacted by tillage treatments. However, tillage had a significant effect on the weed spread $(p<0.05)$, and it was seen that the weed spread at the $\mathrm{T} 1$ and $\mathrm{T} 2$ treatments had a less opportunity for growth. The economic analysis of each application was made by using the revenue / expense ratio. As a result of this economic analysis, the lowest and highest values were obtained 1.89 and 2.70 at $\mathrm{T} 3$ and $\mathrm{T} 1$ applications respectively.

Key Words: Pistachio, weed density, tillage, yield

\section{GíRiş}

Kültür bitkilerinde ürün verimi, tohum kalitesi, is yükü ve üretim masraflarını olumsuz yönde etkileyen faktörlerden biri de yabancı otlardır. Kültür bitkisi içerisindeki yabancı otların bitkiye zarar vermeye başladığı noktada yok edilmesi, kültür bitkisinde verim ve kaliteyi artırır (Özer, 1993). Gelişmiş ülkelerde yabancı otlardan kaynaklanan ürün kayıları ortalama \% 10-15 arasında iken, bazı Asya ülkelerinde bu oran \% 45'e varmaktadır (Gürsoy, 1982). Ancak kültür bitkisine göre yabancı otlardan kaynaklanan verim kayıpları büyük farklılık göstermektedir (Önen ve ark., 1997). Dolayısıyla başarılı bir bitkisel üretim için yabancı ot kontrolü büyük önem taşımaktadır.

Yabancı ot tohumlarının çimlenmesi ve büyümesi güneş, 1şık, toprak nemi gibi birtakım faktörlerin etkisi altındadır. $\mathrm{Bu}$ faktörlerin yanında kullanılan toprak işleme aleti de yabancı ota önemli derecede etki etmektedir. Yabancı ot populasyonunun toprak işleme yöntemi ve buna ilave olarak yabancı otların yaşam süresinin ve dormansi durumuna göre değiştiği, özellikle toprağı devirmeden işleyen aletlerin büyük yabancı ot sorunu oluşturduğu belirtilmektedir (Kocatürk, 1990; Akbolat ve Barut, 2001).

Yabanc1 ot kontrol yönteminin seçimi geniş ölçüde mevcut kültür bitkisine, yabanc1 ot türlerine, toprak tipine, iklimsel şartlara, uygulanan toprak işleme sistemine vb. bağlıdır (Derksen ve ark., 1993; Önen 1999). Bütün toprak işleme sistemlerinde temel olarak tohum yatağının hazırlığı hedeflenirken aynı zamanda yabancı otlarla da mücadele edilmektedir. Ancak toprak işleme sistemine bağlı olarak farklı toprak işleme makineleri kullanıldığından; toprak dolayısıyla da yabancı ot popülasyonları uygulanan toprak işleme sisteminden farklı düzeylerde etkilenir (Streit ve ark., 2003). Kulaklı pulluk ve diskli tırmık gibi aletlerin kullanıldığ geleneksel toprak işleme sistemlerinde bazı yabancı otlar başarılı bir şekilde kontrol altına alınabilinmektedir. Ancak, geleneksel toprak işleme yöntemlerinde toprak alt üst edildiğinden bir önceki y1l toprağa gömülen tohumlar bir sonraki y1l yüzeye çıkartılarak çimlenmeleri teşvik edilmektedir. Toprağın alt üst edilmediği, belli miktarda veya tüm anızın yüzeyde bırakıldığı korumalı toprak işleme sistemlerinde ise bu sorun görülmez. Ancak bu sistemlerde toprak işleme yapılmadığından yabancı ot kontrolü tamamen herbisitlere dayanır (Unger, 1990).

Toprak işleme, ekim zamanı, tohum miktarı, çeşit, gübreleme, ekim nöbeti gibi uygulamalar buğdaydaki yabancı ot yoğunluğunu önemli ölçüde etkilemekte, tekniğe uygun işlemlerle ot yoğunluğunu belirli bir düzeyin altında tutmak mümkün olmaktadır. $\mathrm{Bu}$ uygulamalar içerisinde en önemli yeri alan çeşit seçimidir. Çeşitler arasında, ekolojiye uyumları açısından farklılık olduğu gibi, yabancı otlarla rekabet yönünden de farklılıklar bulunmaktadır. Birim alana ekilen tohum miktarı, yabancı of kuru ağırlığını yani yabancı ot gelişimini etkilediği gibi birim alandaki 
yabanc1 ot sayısını da etkilemektedir (Durutan, 1987). Yabancı otlar kültür bitkilerinde çeşitli etmenlerin meydana getirdiği ürün kayıplarından daha fazla zarara sebep olmaktadırlar (Özer, 1993). Cramer (1967), yabancı otların tüm tarımsal üretimde \% 9.7'lik bir azalmaya neden olduğunu bildirmiştir. Parker ve Fryer (1975) ve Cramer (1967) yapmış oldukları değerlendirmede zararın tüm dünyada \% 14.6 olduğunu saptamışlardır.

Sulama ve gübreleme olanaklarının artması ile hızla çoğalan yabancı otlar meyve bahçelerinde ağaçların suyuna ve besin maddelerine ortak olmak, hasad güçleştirmek ve diğer hastalık ve zararlılara konukçuluk yapmak gibi olumsuzluklara sebep olmaktadır.

Antepfistığı yaygın olarak yetiştiriciliği yapılan ve tüketimi oldukça fazla olan bir meyvedir. Dünyada en çok antepfistığ 1 üreten ülkeler olarak İran ve ABD'den sonra ülkemiz üçüncü sırada gelmektedir.

Tarımsal üretimde yabancı ot kontrolü amaciyla birçok yöntem geliştirilmiş ve bunlar değişik biçimlerde ve bazen tek başına bazen de birbirini tamamlayacak şekilde uygulana gelmiştir. Bu yöntemler temel olarak, mekanik, biyolojik ve kimyasal mücadele başlıkları altında toplanabilir.

Bu çalışmanın amacı, Gaziantep ilinde yaygın olarak üretimi yapılan antepfistığ 1 bahçelerinde; farklı toprak işleme sistemlerinin yabancı ot idaresi yönüyle karşılaştırılması, uygulanan farklı toprak işleme sistemine bağlı olarak yabancı ot tür ve yoğunlukları arasındaki farklılıkların belirlenmesi, toprak işleme sistemlerinin antepfistığı verimine olan etkilerinin araştırılması ve yabancı otlarla kimyasal savaş mücadelesindeki etkinliğin uygulanan toprak işleme sistemine bağlı olarak karşılaştırılmasıdır.

\section{MATERYAL ve METOT}

Bahçe denemeleri, 2006-2008 yıllarında Antepfistığg Araştırma İstasyonu Müdürlüğü Fıstıklık işletmesine ait 8.6 da'lık bir alanda kuru koşularda üçer tekerrürlü olarak yürütülmüstür. Deneme alanından sürüm öncesi 0-20 cm derinlikten bozulmuş toprak örneği alınmıș ve deneme alanı topraklarının killi toprak tekstürüne (\% 4.51 kum, \% 36.5 silt, \% 58.95 kil) sahip olduğu belirlenmiştir. Ayrıca iki farklı derinlikten $(0-10 \mathrm{~cm}$ ve $10-20 \mathrm{~cm}$ ) bozulmamış toprak örnekleri alınmıș ve laboratuvar çalışmaları sonucu deneme alanına ait elde edilen toprak özellikler değerleri Çizelge 1'de verilmiştir.
Çizelge 1. Toprak ișleme öncesi deneme alanı toprak özellikleri

\begin{tabular}{lcc}
\hline \multirow{2}{*}{ Toprak Özellikleri } & \multicolumn{2}{c}{ Derinlik } \\
\cline { 2 - 3 } & $0-10 \mathrm{~cm}$ & $10-20 \mathrm{~cm}$ \\
\hline Nem içeriği (\%) & 10.80 & 11.11 \\
Hacim ağırlı̆̆ $\left(\mathrm{g} \mathrm{cm}^{-3}\right)$ & 0.982 & 1.093 \\
Porozite (\%) & 61.85 & 57.56 \\
Penetrasyon direnci (MPa) & 2.42 & \multicolumn{2}{c}{3.77} \\
pH & \multicolumn{2}{c}{8.0} \\
Kireç (\%) & \multicolumn{2}{c}{8.8} \\
Tuz (\%) & \multicolumn{2}{c}{0.04} \\
Organik madde (\%) & \multicolumn{2}{c}{2.0} \\
\hline
\end{tabular}

Deneme alanından bozulmuş ve bozulmamıș toprak örnekleri alınarak fiziksel ve kimyasal özellikleri belirlenmiştir. Bozulmuş toprak örnekleri 0-10 ve 10-20 $\mathrm{cm}$ derinliklerindeki katmanlardan, toprak burgusu kullanılarak alınmıştır. Deneme alanında, iki farklı derinlikten (0-10 ve $10-20 \mathrm{~cm})$ alınan bozulmamış toprak örnekleri etüvde $105{ }^{\circ} \mathrm{C}$ 'de sabit ağırlığa gelene kadar 24 h süre ile kurutulduktan sonra kuru baza göre nem içeriği standart yöntem kullanılarak hesaplanmıştır (Sağlam ve ark., 2014).

Toprak işleme uygulamalarında güç kaynağ 1 olarak Ford 3000 marka standart bir traktör, toprak işleme aletleri olarak da kulaklı pulluk ve bahçe kültivatörü kullanılmıştır. Denemelerde kullanılan tarım aletlerine ait bazı teknik özellikler Çizelge 2'de verilmiştir.

Çizelge 2. Denemede kullanılan tarım makinalarına ait teknik özellikler

\begin{tabular}{lccc}
\hline \multicolumn{1}{c}{ Özellikler } & Traktör & $\begin{array}{c}\text { Kulaklı } \\
\text { Pulluk }\end{array}$ & Kültivatör \\
\hline Güç (kW) & 35 & - & - \\
Gövde/Ayak sayısı & & 3 & 9 \\
Ağırlık (kg) & & 240 & 461 \\
Uç demiri tipi & & Avrupa & Kazayağ1 \\
İş genişliği (cm) & & 103.5 & 225 \\
İş derinliği $(\mathrm{cm})$ & & $20-30$ & 25 \\
\hline
\end{tabular}

Deneme alanında yaklaşık 37 yaşlarında olan ve Pistacia vera anac1 üzerine așılı "Uzun" çeșidi antepfistığı ağaçları yetiştirilmektedir. Antepfistığı ağaçlarının sıra arası ve sıra üzeri mesafeleri 8 m'dir. Üretim kuru koşullarda yürütülmektedir. Deneme parselleri her üç sıra bir parsel olacak şekilde $(24 \mathrm{~m})$ ve bir sıra arası tampon olacak şekilde kurulmuştur. Parsel uzunluğu $40 \mathrm{~m}$ olarak alınmıştır. Araştırmada üç farklı toprak işleme uygulamasının etkisi üç tekerrürlü olarak incelenmiş ve deneme parselleri tesadüf blokları deneme desenine göre kurulmuştur.

Uygulanan toprak işleme uygulamaları aşağıdaki işlem zincirinde gerçekleştirilmiştir.

- Geleneksel toprak işleme 1 (T1) : Kulaklı pulluk (kışın) + Kültüvatör (ilkbaharda) + İlaçlama (herbisit) (ilkbaharda)

- Azaltılmıș toprak işleme (T2) : Kulaklı pulluk (kıșın) + Kültüvatör (ilkbaharda)

- Geleneksel toprak işleme 2 (T3) : Kulaklı pulluk (kışın) + Kültüvatör (ilkbaharda iki kez, yaz ve sonbaharda bir kez) 
Kulaklı pullukla yapılan sürümler derin sürüm ve külttüvatör ile yapılan sürümler yüzeysel sürüm olacak şekilde yapılmıştır. Sadece birinci uygulamada yabancı ot ile mücadelede herbisit uygulaması yapılmış diğer uygulamada mekanik mücadele uygulaması seçilmiştir. Kimyasal mücadelede Glyphosate/Round-up ULTRA herbisit ilacı ile $800 \mathrm{cc} \mathrm{da}^{-1}$ olacak şekilde TARAL 100$S$ pülverizatörü ile uygulanmıştır.

Yabancı otların yoğunlukları belirlenirken $50 \times 50 \mathrm{~cm}$ boyutlarına sahip çerçeve kullanılmış ve ölçümler kenar tesirinden mümkün olduğu kadar kaçınılarak bahçe köşegenlerinden $10 \mathrm{~m}$ içeriden yapılmıştır. Çerçeve, şansa bağlı olarak her parselde 2 kez atılarak, içerisindeki yabancı otların cins veya türleri üzerinden sayımlar yapılmıştır. Daha sonra her iki sayımın ortalaması alınarak $\mathrm{m}^{2}$ 'deki yabancı ot yoğunluğu bulunmuştur.

Araștırma alanlarındaki yabancı ot türlerinin dağılışlarının homojen veya heterojenliği hakkında bilgi edinmek için rastlama sıklıkları (\%) saptanmıştır. Bunun için, 1 nolu eşitlik kullanılmıștır (Uygur, 1985).

Yabanc1 ot yoğunluğu $(\%)=(\mathrm{n} / \mathrm{m}) \times 100$

Burada,

n : bir türün rastlandığı çerçeve sayısı (adet) ve

m : atılan toplam çerçeve sayısıdır (adet).

Verim değerleri hesaplanırken; hasat zaman ağaçların altında bulunan kuru meyveler toplanmış, daha sonra ağaçların altına bez (şal) serilerek meyve salkımları toplanmıştır. Meyveler salkım saplarından ayrılarak, seçilmiş ve her parselde bulunan 3 ağaçtan alınan meyve miktarları yaş olarak tartılmıştır. Her parseli temsil edecek şekilde $1 \mathrm{~kg}$ yaş meyve alınarak oda koşullarında kurutulmuş, arazide alınan yaş meyve değerleri kuru ağırlığı çevrilerek ağaç başına ve dekardan alınan kuru kırmızı kabuklu meyve miktarlar ( $\mathrm{kg}$ ağaç ${ }^{-1} \mathrm{ve} \mathrm{kg} \mathrm{da}^{-1}$ olarak) hesaplanmıştır (Atlı ve ark., 1999).

Elde edilen veriler kullanılarak uygulamalar arasındaki farklılıkların önem derecelerini belirlemek ve ortalamalar arasındaki farklılıkları görebilmek için de çoklu karşılaştırma testleri (LSD) yapılmıştır.

\section{BULGULAR ve TARTISMA}

Uygulama alanındaki üç yıllık ortalama verim değerleri istatistiksel olarak değerlendirildiğinde uygulamalar arasında fark olmadığı saptanmıştır (Çizelge 3).

Çizelge 3. Antepfistığı ürün verim değerleri

\begin{tabular}{lcc}
\hline $\begin{array}{l}\text { Toprak işleme } \\
\text { uygulamaları }\end{array}$ & $\begin{array}{c}\text { Verim } \\
\left(\mathrm{kg} \mathrm{ağaç}^{-1}\right)\end{array}$ & $\begin{array}{c}\text { Verim } \\
\left(\mathrm{kg} \mathrm{da}^{-1}\right)\end{array}$ \\
\hline Geleneksel toprak işleme 1 (T1) & 9.70 & 145.53 \\
Azaltılmış toprak işleme (T2) & 9.73 & 145.95 \\
Geleneksel toprak işleme 2 (T3) & 8.19 & 122.85 \\
\hline LSD $(\% 5)$ & $\mathrm{ns}$ & $\mathrm{ns}$ \\
\hline${ }^{*} \mathrm{p}<0.05, * * \mathrm{p}<0.01$, ns: önemsiz & &
\end{tabular}

Yıllar ortalaması açısından ağaç başı ve dekara verim değerleri incelendiğinde, en yüksek ağaç başı verim değerinin $9.73 \mathrm{~kg}$ ağaç ${ }^{-1}$ ile kışın kulaklı pulluk ve ilkbaharda kültivatörle yüzeysel sürümün yapıldığı T2 uygulamasından elde edildiği belirlenmiștir. Özellikle dekara verimin geleneksel sürümün yapıldığı T3 uygulamasında diğer uygulamalara göre daha düşük olduğu tespit edilmiştir. Gaziantep yöresinde Antepfistığı yetiştiriciliğinde kuru tarım (sulama yapılmıyor) uygulanmaktadır. Geleneksel uygulamada çok sayıda yapılan toprak işleme uygulaması toprakta nem kaybına sebep olmaktadır. Bitkinin yararlanacağı nemin topraktan kaybolması ise doğrudan verime etki etmektedir. Buna göre en yüksek verim değeri toprak işleme uygulamasının en az yapıldığı T2 uygulamasından elde edilirken en düşük verim değeri $\mathrm{T} 3$ uygulamasında elde edilmişsir.

Toprak işleme uygulamalarına bağlı olarak herbisit uygulanmayan $\mathrm{T} 2$ ve $\mathrm{T} 3$ parsellerinde toplam bitki sayısı sirasiyla 47.96 bitki $\mathrm{m}^{-2}$ ve 48.07 bitki $\mathrm{m}^{-2}$, herbisit uygulanan parsel de (T1) ise 46.70 bitki $\mathrm{m}^{-2}$ olarak belirlenmiştir. Toprak işleme uygulamasına bağlı olarak metrekarede yabancı ot yoğunluğu bakımından istatistiksel bir farklılık saptanmamıştır $(\mathrm{p}<0.05)$. Yabancı otların genel kaplama alanı; geleneksel uygulama yapılan T3 uygulamasinda \% 61.40 ile en yüksek bulunmus, bunu sirasiyla; \% 58.34 ile T1 ve \% 59.01 ile T2 uygulamaları takip etmiştir ve aradaki farklar istatistiksel olarak $\quad(p<0.05)$ önemli bulunmuştur. Dolayısıyla metrekaredeki bitki sayıları daha düşük olsa da genel kaplama alanları göz önüne alındığında $\mathrm{T} 2$ ve $\mathrm{T} 1$ uygulamalarında yabancı otların daha az gelişme olanağı bulduğu söylenebilir (Çizelge 4).

Çizelge 4. Yabancı ot yoğunluğu ve rastlama sıklığı

\begin{tabular}{lcc}
\hline Toprak işleme uygulamaları & $\begin{array}{c}\text { Kaplama } \\
\text { alan1 (\%) }\end{array}$ & $\begin{array}{c}\text { Yoğunluk } \\
\left(\text { adet m }^{-2}\right)\end{array}$ \\
\hline Toprak işleme-Herbisit (T1) & $58.34 * \mathrm{~b}$ & $46.70 \mathrm{~ns}$ \\
Azaltılmış toprak işleme (T2) & $59.01 * \mathrm{ab}$ & $47.96 \mathrm{~ns}$ \\
Geleneksel toprak işleme (T3) & $61.40 * \mathrm{a}$ & $48.07 \mathrm{~ns}$ \\
\hline$*$ p $<0.05, * * \mathrm{p}<0.01, \mathrm{~ns}$ önemsiz & &
\end{tabular}

Yabancı ot türleri teker teker ele alındığında birim alandaki bitki sayılarında uygulanan toprak işleme uygulamasina göre farklılıklar görülmüştür. Deneme alanında; Anthemis arvensis L. (papatya) yabancı ot türünün T1 uygulamasında, Veronica arvensis L.(tarla yavşan otu) yabanc1 ot türünün $\mathrm{T} 2$ uygulamasında ve Papaver rhoes $L$. (gelincik) yabanc1 ot türünün ise T3 uygulamasında yaygın karşılaşılan türler olduğu tespit edilmiştir (Şekil 1). ABD'de 4 yıl boyunca yapılan çalışmalarda da toprak işleme uygulamalarına bağlı olarak bazı yabancı otların popülasyonu azalırken bazılarında ise artış olmuştur (Hayes, 1982). Ancak toprak işleme yöntemine ve kültür bitkisine bağlı olarak aynı bölgede bulunan tarlalar hatta aynı tarla içerisinde dahi yabancı otlanma yönüyle homojen bir dağılım olmadığ 1 belirtilmiştir (Young, 1982; Tücer ve Önal, 1997; Özer ve ark., 2001) 


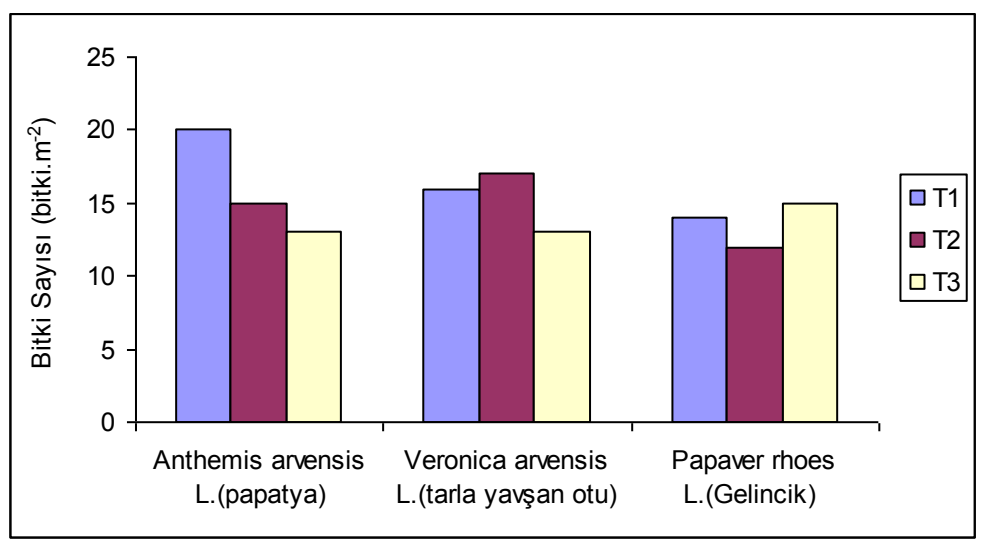

Şekil 1. En yaygın üç yabancı ot türünün uygulama alanlarındaki dağılımı

Uygulamaların masraf unsurları ve toplam maliyeti belirlenirken bölge koşullarında antepfıstığı üretiminin ekonomik analizinde ürün birim satıș fiyatları ve makine kiralama bedelleri esas alınmıștır. Denemeler sirasında kullanılan girdiler ve makinelerine ait kiralama bedelleri Çizelge 5'de verilmiştir.

Çizelge 5. Farklı uygulamalara ait değerlerin ekonomik analizi

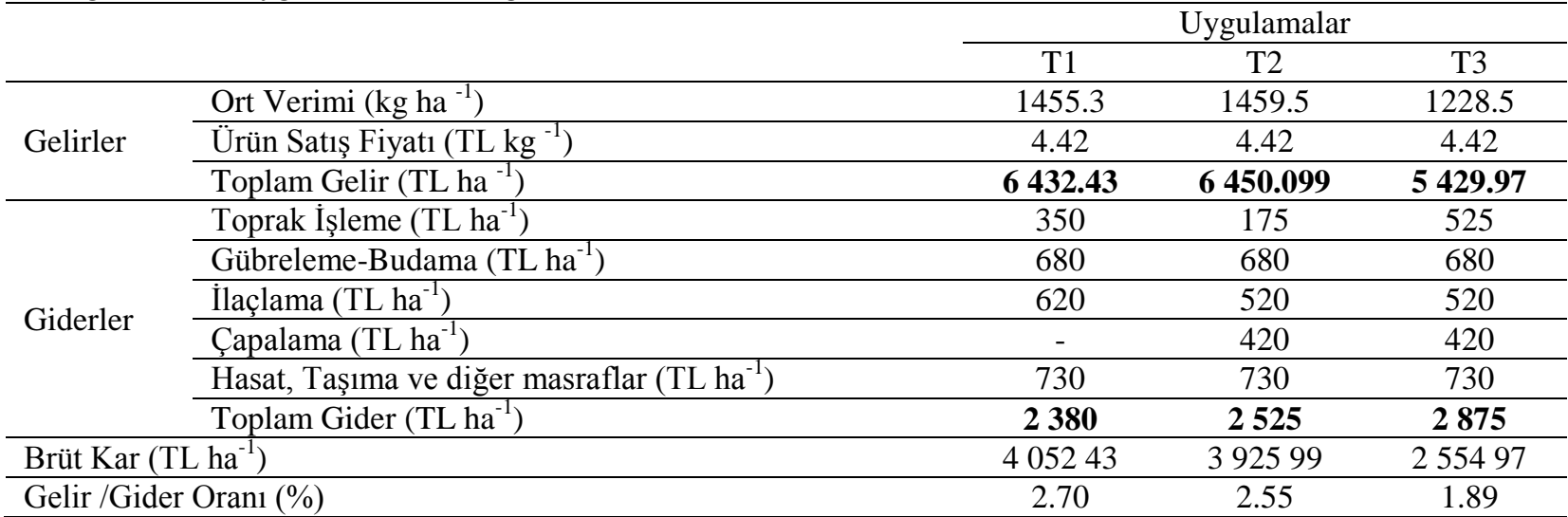

Gider tablosu incelendiğinde, en yüksek gider 2875 $\mathrm{TL} \mathrm{ha}^{-1}$ lik T3 uygulamasında gerçekleşmiştir. T2 ve T1 uygulamasında toplam gider değerleri sirasıyla $2525 \mathrm{TL}$ ha $^{-1}$ ve 2380 TL ha ${ }^{-1}$ olarak hesaplanmıştır. Uygulamalara ilişkin ekonomik değerlendirmenin yapılabilmesi için birim alandaki toplam giderlerin yanı sira elde edilen toplam gelirlerin de detaylı bir şekilde belirlenmesi gerekmektedir. Bu amaçla, gelir bileşenleri antepfistığ1 veriminden elde edilen gelir olarak saptanmış ve hesaplamalar yapılmıştır. Uygulamalara göre elde edilen gelir değerleri ile ekonomiklik konusunda karar verilmesini ve uygulamalar arası karşılaştırma yapılmasını sağlayacak gelir/gider oranları Çizelge 5'de verilmiştir. Buna göre, en düşük gelir/gider oranı 1.89 olarak T3 uygulamasında elde edilmiştir. En yüksek oran ise T1 uygulamasında 2.70 olarak belirlenmiştir. Buna göre incelenen koşullar altında en kârlı uygulamasının; Kulaklı pulluk (kışın) + Kültüvatör (ilkbaharda) + İlaçlama (herbisit) (ilkbaharda) uygulamalarının yapıldığ $\mathrm{T} 1$ uygulaması olduğu söylenebilir.

\section{TARTIŞMA ve SONUÇ}

Antepfistığı bahçelerinde değişik toprak işleme uygulamalarının verim ve yabancı ot yoğunluğu üzerine etkilerini belirlemek amacıyla yapılan bu çalışma da, özellikle T2 yöntemi yabancı ot yoğunluğunda azalmaya neden olmuştur. Metrekaredeki bitki sayıları daha düşük olsa da genel kaplama alanları göz önüne alındığında T2 ve T1 uygulamalarında yabancı otların daha az gelişme olanağı bulduğu söylenebilir. Yabancı otların gerek metrekaredeki bitki sayıları gerekse genel kaplama alanları açısından en olumsuz uygulamanın geleneksel uygulamanın yapıldığı T3 uygulaması olmuştur. Yabanc1 ot mücadelesinde toprak işleme de kullanılan alet ve işleme zamanı önemli faktörler olmaktadır. Deneme sonuçlarından da anlaşılacağı üzere, mekanik mücadele tek başına yeterli olmayıp, kimyasal mücadele ile de desteklenmelidir. Ayrica deneme de, geleneksel uygulamanın yapıldığı T3 uygulamasının en fazla otlanmayı sağlamas1, üreticilerimizin bu uygulamadan vazgeçerek toprakta daha az geçişin olduğu uygulamalara yer vermesi bakımından da önemli olduğunu göstermiştir. Verim açısından her üç toprak işleme yöntemi arasında 
istatistiksel farklılık görülmese de özellikle tarla trafiğinin azalması, yakıt tüketimi ve iş gücü gereksiniminin düşük olması ayrıca birim girdiye karşı elde edilen gelir oranının daha yüksek olması nedeniyle T1 (Herbisit uygulaması) uygulamasının önerilmesi gereği ortaya çıkmaktadır.

\section{KAYNAKLAR}

Akbolat, D., Barut, Z.B. 2001. Anızlı ve anızsız toprak işlemenin yabancı ot gelişimine etkisi. Tarımsal Mekanizasyon 20. Ulusal Kongresi Bildiri Kitab1, Şanliurfa, 85-90.

Atlı, H. S., Arpacı S., Akgün A., Özgüven A. I., Özgüven, F. 1999. Bazı Antepfıstığı Çeşitlerinin Hasat Zamanının Saptanması ve Makineli Hasadın Uygulanabilme Durumunun Araştırılması. Türkiye III. Ulusal Bahçe Bit. Kong. S.248 - 251.Ankara.

Cramer, H.H. 1967. Pflanzenschutz und Welternte. Pflanzenschutz Nachrichten Bayer Leverkusen, 20: $1-523$.

Derksen, D.A. Lafond, G.P., Thomas, A.G., Loeppky, H.A., Swanton, C.J. 1993. Impact of agronomic practices on weed communities: Tillage systems. Weed Science, 41, 409-417.

Durutan, N. 1987. Orta Anadolu Bölgesi koşullarında buğdayda entegre yabanc1 ot kontrolü. Türkiye Tahıl Sempozyumu, 6-9 Ekim 1987, Bursa, 211-223.

Gürsoy, O.V. 1982. Yabanc1 ot kontrolünün temel esasları ve Şeker pancarı tarımında tatbiki. Türkiye Şeker Fabrikaları A. Ş., Şeker Enstitüsü Yayını, Etimesgut-Ankara.

Hayes, W. A. 1982. Minimum-Tillage Farming. No Till Farmer, Inc. Brocfield, Winsconsin.

Önen H., Özer, Z., Tursun, N. 1997. Kazova (Tokat)'da yetiştirilen Şeker Pancarı (Beta vulgaris var. Altissima D.C.) verimine yabancı otların etkileri üzerinde araştırmalar. Türkiye II. Herboloji Kongresi, İzmir-Ayvalık.

Önen, H. 1999. Pelin (Artemisia vulgaris L.)'in Bazı Biyolojik Özellikleri ile Savaşım Olanakları Üzerinde Araştırmalar. Gaziosmanpaşa Üniversitesi Fen Bilimleri Enstitüsü Bitki Koruma Anabilim Dali, Doktora Tezi,149 s., Tokat.
Özer, Z. 1993. Niçin yabancı ot bilimi (Herboloji). Türkiye I. Herboloji Kongresi, 3-5 Şubat, Bildiriler, Adana.

Özer, Z., Kadığlu, İ., Önen, H., Tursun, N. 2001. Herboloji (Yabancı Ot Bilimi). Genişletilmiş 3. Bask1. Gaziosmanpaşa Üniversitesi Ziraat Fakültesi Yayınları No: 20. Kitaplar Serisi No:10. GOPÜ Basımevi, Tokat.

Kocatürk, Ü. 1990. Buğdayda Farklı Toprak İşleme Yöntemlerinin Yabancı Ot Popülasyonuna Etkileri. Yüksek Lisans Tezi). Ege Üniversitesi Fen Bilimleri Enstitüsü Bitki Koruma Anabilim Dalı, Bornova, İzmir 67s.

Parker, C., Fryer, J. 1975. Weed control problems causing major reduction in world food supplies. FAO Plant Protec. Bull. 23 (3/4): 83-95.

Sağlam, M., Selvi, K.Ç., Dengiz, O., Gürsoy, F.E. 2014. Affects of different tillage managements on soil physical quality in a clayey soil. Environmental Monitoring and Assesment. Vol:187. No:1. 4185. p: 2-12

Streit, B., Rieger, S.B., Stamp, P., Richner, W. 2003. Weed populations in winter wheat as affected by crop sequence, intensity of tillage and time of herbicide application in a cool and humid climate. Weed Research, 43, (1) 20-32.

Tücer, A., Önal, İ. 1997. Farklı Toprak İşleme Sistemlerinde Bitki Hastalıkları, Zararlıları, Yabancı Otlar Ve Bunlarla Mücadele Yöntemleri. Tarımsal Mekanizasyon 17. Ulusal Kongresi, 17-19 Eylül, Tokat.

Unger, P.W. 1990. Conservation Tillage Systems. Advance in Soil Science, 13:27-67.

Uygur, F.N. 1985. Untersuchungen $\mathrm{zu}$ Art und Bedeutung der Berücksictigung von Cynodon dactylon (L.) Pers. und Sorghum halepense (L.) PLITS, Verlag: Josef Margraf, Stuttgart, 3 (5). 